\title{
Modelling the effects of needle mortality rate and needle area distribution on dry matter production of Douglas fir
}

\author{
G. M. J. MOHREN' \& H. H. BARTELINK2 \\ 1 Division of Forestry, Research Institute for Forestry and Urban Ecology 'De Dorsch- \\ kamp', P.O. Box 23, NL 6700 AA Wageningen, Netherlands \\ 2 Department of Theoretical Production Ecology, Wageningen Agricultural University, \\ P.O. Box 430, NL 6700 AK Wageningen, Netherlands (present address: Department of \\ Forestry, Wageningen Agricultural University, P.O. Box 342, NL 6700 AH Wageningen, \\ Netherlands)
}

Received 9 August 1989; accepted 9 November 1989

\begin{abstract}
A physiological simulation model is used to analyse the effects of increased needle mortality rate and changes in needle area distribution on the primary production of a Douglas fir stand. Needle life-span may decrease as a result of air pollution and soil acidification, and is an important aspect of forest decline. The results presented show that simulation models can be used to study possible consequences of these phenomena in forest stands. The model is used to quantify the'relationship between total leaf area index (LAI) and stand growth, taking into account different light distributions within the canopy that result from needle area distribution and clustering of needles. It is shown that the effect of an increase in needle mortality rate is strongly dependent on initial LAI. At low initial LAI, productivity will decrease as a result of an increase in needle mortality and decreased light interception; at high initial LAI, light interception does not necessarily decrease significantly when needle mortality increases, but productivity may even increase because of decreased maintenance respiration. These effects may vary between stands and between species; deterministic simulation models can clarify the underlying mechanisms.
\end{abstract}

Keywords: LAI, needle longevity, needle distribution, Douglas fir, primary production, canopy assimilation, forest growth

\section{Introduction}

Potential forest growth is determined by temperature and the amount of photosynthetically active radiation (light) that is absorbed by the foliage. Temperature and radiation above the canopy are site conditions, mainly determined by latitude, cloudiness and time of the year. The fraction of incoming radiation that is intercepted and absorbed by the canopy depends on the total amount of foliage surface area, 
expressed as leaf area index (LAI, in $\mathrm{m}^{2}$ projected leaf area per $\mathrm{m}^{2}$ soil surface), the distribution of foliage inside the canopy, and the radiation characteristics of the foliage. The three-dimensional distribution of foliage surface area inside the canopy determines light extinction inside the crown canopy and the light distribution over the foliage elements. As photosynthesis is non-linearly related to the amount of light absorbed per unit of foliage, distribution of light over the foliage influences total canopy assimilation. In this paper, the effects of needle longevity, of total needle biomass, and of needle distribution on total stand productivity are investigated using a simulation model for Douglas fir in the Netherlands.

The life-span of the foliage of coniferous trees usually exceeds a single growing season. Douglas fir growing in the Netherlands can have a needle life-span of up to five years, occasionally up to ten years. Needle shedding may occur throughout the year, but new needles are only formed during spring after budflush. As a result of this periodicity in needle growth, total needle biomass can be separated into a number of distinct age-classes. The distribution of these age-classes within the tree crowns is determined by the formation of new needles mainly at the top of the canopy and on the outside of the crown volume, and by needle mortality. Needle loss depends on ageing of the tissue, determined by physiological properties in combination with microclimatic conditions such as light levels and relative humidity in the different parts of the crown.

Potential photosynthetic activity decreases with needle age. The highest assimilation rates occur in fully developed new needles. When needles age, morphological changes occur: nitrogen content and the amount of the carboxylating enzyme ribulose biphosphate carboxylase-oxygenase (Rubisco) decrease and water content declines (Freeland, 1952; Smith, 1972; Zajaczkowska et al., 1981). Morphological and photosynthetic properties thus vary between needle age-classes, and changes in the distribution of foliage biomass over the age-classes may lead to changes in total canopy assimilation. Air pollution and nutrient deficiencies resulting from soil acidification may increase the needle mortality rate (Zajaczkowska et al., 1981), thereby decreasing total needle area, and changing the age-class distribution. As a result of this decrease in LAI, light interception will be decreased, leading to less absorption of photosynthetically active radiation. Needle life-span may be influenced differently in different positions in the canopy as a result of different exposure, and the spatial distribution of the individual needle age-classes may also be affected.

The effects of increased needle mortality rate on canopy assimilation and dry matter production are difficult to measure in the field. Therefore, simulation models of forest growth that are based on underlying principles of light absorption, photosynthesis, and canopy assimilation are very useful for analysing the quantitative aspects of these relationships.

\section{Aim and methods}

The aim of this study was to quantify the effects of needle mortality rate and distribution of needle area inside the canopy on dry matter production in even-aged 
Douglas fir stands (Pseudotsuga menziesii (Mirb.) Franco) in the Netherlands. Douglas fir was selected for a case-study because of the availability of physiological data on this species, and because of its importance in current acidification research in the Netherlands (Evers et al., 1987). A comprehensive physiological simulation model for the growth of Douglas fir in the Netherlands was published recently (Mohren, 1987). Based on this model and on the SUCROS general summary model for plant growth (Spitters et al., 1989), a simulation model was developed to analyse the influence of LAI and of changes in the distribution of needle age-classes.

In the model, canopy assimilation is calculated from the distribution of light over the needles in the canopy, using a negative exponential photosynthesis-light response curve to calculate $\mathrm{CO}_{2}$ uptake per unit of needle area. Douglas fir needles may live for up to 10 years (Silver, 1962) but generally about $95 \%$ of the foliar weight falls into age-classes less than 5 years old (Silver, 1962; Kay, 1978). This holds for Dutch sites too (Mohren, 1987). In the present model, five age-classes are taken into account (current-year needles, one-year-old, two-year-old, three-yearold, and four-year-old needles). Needles older than four years are ignored. Each age-class has specific photosynthetic properties, such as maximum photosynthesis at light saturation. For all age classes, a value of $11.2 \mu \mathrm{g} \mathrm{CO}_{2} \mathrm{~J}^{-1}$ was used for the initial light use efficiency at low light intensity. For the rate of maximum gross photosynthesis at light saturation $\left(A_{\text {max }}\right)$ the values used for current, one-year-old, two-year-old, three-year-old, and four-year-old needles were 17.1, 14.8, 11.3, 8.6, and $6.9 \mathrm{~kg} \mathrm{CO}_{2} \mathrm{ha}^{-1} \mathrm{~h}^{-1}$, respectively. The values for $A_{\max }$ apply to optimum temperature for photosynthesis. For Douglas fir, the optimum range was taken to be from $13{ }^{\circ} \mathrm{C}$ to $25^{\circ} \mathrm{C}$. It was assumed that below $13{ }^{\circ} \mathrm{C}$, photosynthesis decreased steadily and at $0{ }^{\circ} \mathrm{C}$ was $10 \%$ of the optimum, and at $-5{ }^{\circ} \mathrm{C}$ was zero. This reduction as a result of suboptimal temperatures was applied to all foliage age-classes. Not only do photosynthesis characteristics vary; the ratio between needle surface area and needle weight, usually called specific leaf area (SLA) also differs between age-classes. Older foliage usually has lower SLA values (Smith, 1972; Kay, 1978) and hence intercepts less radiation per unit of weight. Microclimatic conditions during needle development affect needle morphology (Del Rio \& Berg, 1979; Borghetti et al., 1986), and as a result SLA per age-class may also vary with depth in the canopy (Smith, 1972; Beadle et al., 1982). As the model simulates biomass weight, and foliage area is subsequently estimated using SLA, this may have to be taken into account in a detailed multilayer model. In the present model, however, constant values depending solely on needle age-class were taken from Borghetti et al. (1986): the values used were $7.7,6.6,5.7,5.5$ and $5.5 \mathrm{~m}^{2} \mathrm{~kg}^{-1}$ with increasing age for the five needle age-classes.

Instantaneous photosynthesis rates per unit needle area for each age-class were integrated over the whole canopy and over the day using a three-point Gaussian numerical method (Goudriaan, 1986b). Complete horizontal canopy closure was assumed in the calculations; gaps in the canopy were not accounted for. Although this assumption may not hold for old forest canopies it was sufficient for our purposes. The canopy was modelled as a single crown layer, with a homogeneous horizontal distribution of needle area. Vertical leaf area distributions were taken into account 
using the approach developed by Spitters (1989) to study competition for light between crops and weeds. In this approach, five foliage layers are distinguished to account for light distribution over five foliage classes that differ in their position in the vertical inside the canopy; individual tree crown characteristics are ignored.

In the model the extinction coefficients are determined by individual leaf characteristics, leaf angle distribution and angle of light incidence. In addition, clustering of foliage around branches and within crowns may affect the light regime. In the case of clustering, light penetration into the deeper layers will increase, while at the same time the internal shading of the needles within the clusters increases. As a result, the model may overestimate the light interception in the top layers of the stand, when a simple, exponential, light extinction model is used. In the case of clustering of needles or leaves, the extinction coefficient used in the model should be lower than the theoretical value calculated for a homogeneous distribution of foliage. In the present model, the approach of the summary model SUCROS (Spitters et al., 1989) was followed, by taking the ratio between an actual extinction coefficient for diffuse light and the theoretical value of $0.8 \times \sqrt{ }(1-\sigma)$ (see Goudriaan, 1977). This ratio is used as an approximation for the degree of clustering $\left(C_{1}\right)$ :

$$
C_{1}=k_{\mathrm{df}, \mathrm{a}} /(0.8 \times \sqrt{ }(1-\sigma))
$$

where $k_{\mathrm{df}, \mathrm{a}}$ is the actual extinction coefficient for the diffuse fraction, and $\sigma$ represents the scattering coefficient of the foliage, which is about 0.1 for visible radiation and conifer foliage (Jarvis et al., 1976). The theoretical value for $k_{\mathrm{df}}$ is constant, calculated under the assumption of a uniformly overcast sky, and depending on the scattering characteristics of the leaves ( $\sigma$ ) only (Goudriaan, 1977).

As described above, the needle biomass was separated into five different ageclasses. It was assumed that there is no loss of current-year needles, but that needle loss starts after the first growing season. The following equation was used to describe the decrease in needle dry weight over time per age-class in the year after the year in which the needles were formed (Mohren, 1987):

$$
W_{i, t}=W_{i, 0} \times \exp \left(-0.5 \times L_{\mathrm{c}} \times t^{2}\right)
$$

in which $L_{\mathrm{c}}$ represents an empirical needle loss coefficient determining the average life-span of the needle biomass. $W_{i, t}$ equals the needle mass in class $i$ at time $t$ (in days since the start of needle loss, after the first growing season); $W_{i, 0}$ equals the total dry weight of the current-year needles at the end of the year in which they were formed, and at the beginning of the second year. All needles remaining in the oldest age-class are assumed to die at the end of the fifth year.

Equation 2 is based on the assumption that the relative needle loss per age-class increases linearly with age after the year in which the needles are formed $(\mathrm{d} W / \mathrm{d} t$ $=L_{\mathrm{c}} \times t \times W$ ). Figure 1 gives an example of an actual age distribution of needle mass over four age-classes (Fig. 1a), together with a fitted simulated distribution using a loss coefficient of $3 \times 10^{-6} \mathrm{~d}^{-2}$. Figure $1 \mathrm{c}$ shows how $L_{\mathrm{c}}$ can be used to fit the simulated distribution to the actual distribution. 

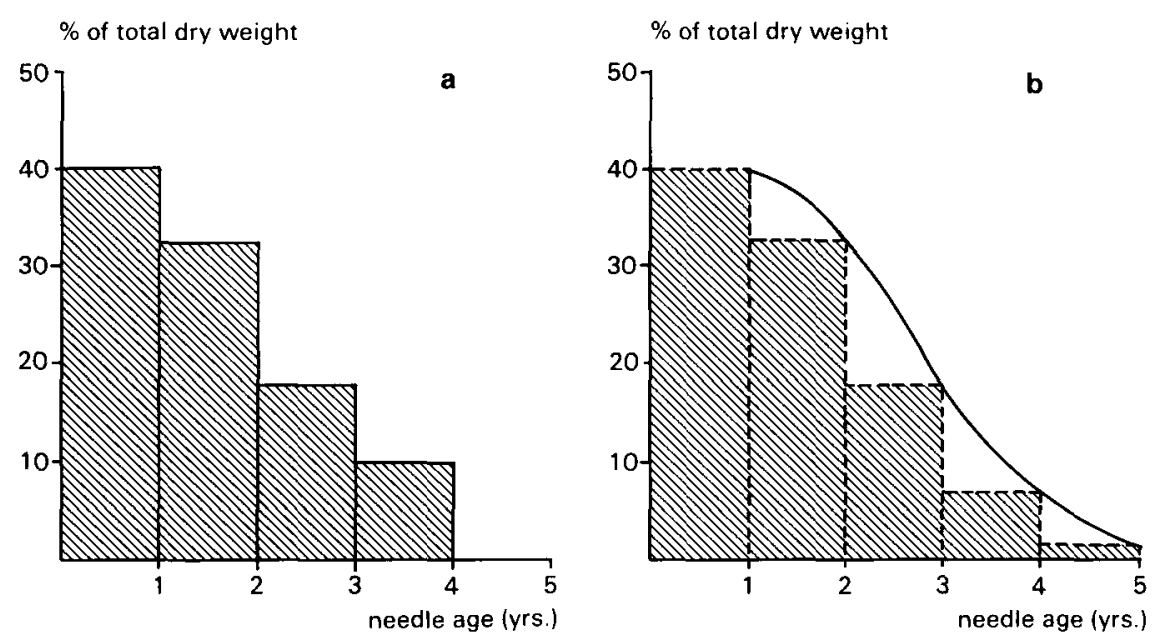

c

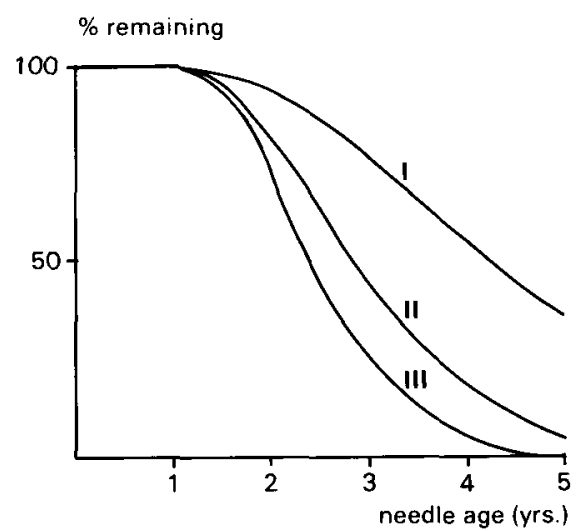

Fig. 1. Observed (a) and simulated (b) needle-age distributions in a Douglas fir stand in the Netherlands. Fig. 1a is taken from Mohren (1987, his Fig. 3.10); in la the needle dry weight was separated into four age-classes only, all older needles were added to the four-year-old class. This explains the difference between observed and simulated for age-classes 4 and 5 . In the simulation shown in $1 \mathrm{~b}$, Equation 2 is used with a loss coefficient $L_{\mathrm{c}}$ of $3 \times 10^{-6} \mathrm{~d}^{-2}$. Fig. 1c shows the sensitivity of the simulated needle-age distribution to changes in $L_{\mathrm{c}}$ : values of 1,3 and $5 \times 10^{-6} \mathrm{~d}^{-2}$ were used for the lines I, II, and III, respectively. Line II corresponds to the drawn line in Fig. $2 b$.

The biomass per age-class is distributed over crown depth according to a simple leaf-area density function (Kinerson \& Fritschen, 1971; see Fig. 2). As a result, needle area and light interception per layer of constant depth vary with increasing depth in the canopy. The instantaneous assimilation rate depends on the amount of absorbed light and the shape of the photosynthesis-light response curve. The amount of light absorbed per unit of needle area was calculated at five heights in the canopy, and at three times of the day, corresponding to the Gaussian integration scheme that 


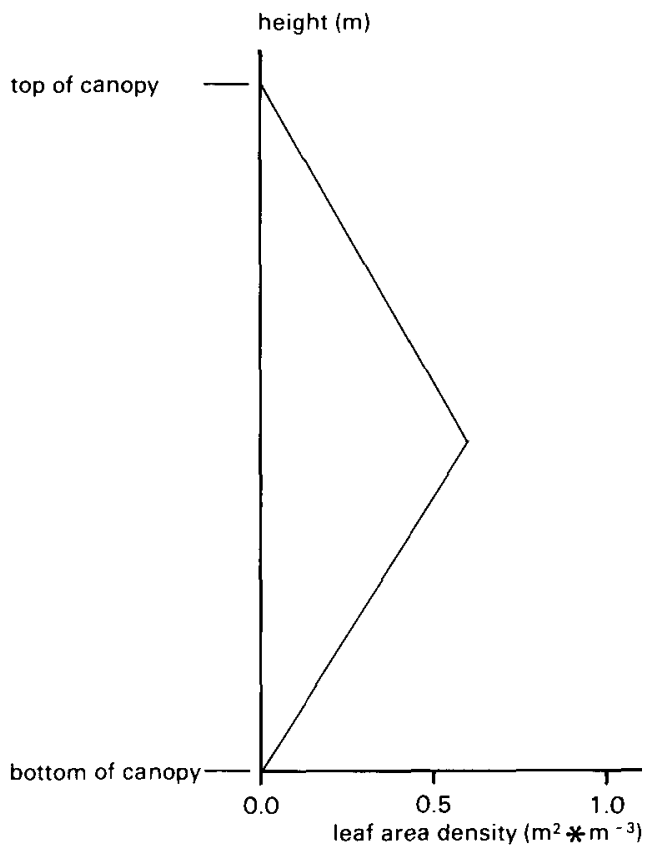

Fig. 2. Distribution of the canopy leaf area over the crown depth according to Kinerson \& Fritschen (1971). Leaf area distribution (LAD) of the current-year needles at the beginning of the simulation run is shown (data taken from Borghetti et al., 1986). Maximum LAD of the current needles amounts to 0.6 $\mathrm{m}^{2} \mathrm{~m}^{-3}$ in the middle of the canopy; total LAD at this height is $1.2 \mathrm{~m}^{2} \mathrm{~m}^{-3}$.

was used. Separate exponential extinctions for both diffuse and direct radiation were used in the model. The fractions of diffuse and direct radiation out of total incoming radiation were calculated according to Spitters et al. (1986).

The fraction of sunlit leaf area $\left(f_{\text {sla }}\right)$ per layer was subsequently used to calculate the average assimilation rate for each layer. Note that the effect of clustering also has to be included in the expression for $f_{\text {sla }}$, to account for mutual shading (Goudriaan, personal communication; see also Spitters et al., 1989): $f_{\mathrm{sla}, i}=C_{1} \times$ $\exp \left(-k_{\mathrm{bl}} \times \mathrm{LAI}_{i}\right)$; where $\mathrm{LAI}_{i}$ is the cumulative leaf area index from the top of the canopy down to layer $i$, and $k_{\mathrm{bl}}$ is the extinction coefficient for the direct component of the fraction of direct radiation (calculated as $C_{1} \times 0.5 / S_{\mathrm{b}}$, with $S_{\mathrm{b}}$ the sine of the solar inclination above the horizon, at each point of the Gaussian integration over the day).

The daily dry matter production was calculated by subtracting maintenance respiration from daily total canopy assimilation. Maintenance respiration was calculated according to Mohren (1987), and amounted to $40-45 \%$ of total gross canopy assimilation. Conversion of assimilates into structural dry matter (growth respiration) involves a weight loss of 30-35 \% of the amount of assimilates available for biomass growth. Dry matter was distributed over the biomass components (needles, 
branches, stems, and roots), using a descriptive allocation pattern that depends on tree age only (Mohren, 1987). The simulations were carried out for a 40-year-old Douglas fir stand, with initial values for the biomass components at the beginning of all simulation runs of $20000 \mathrm{~kg} \mathrm{ha}^{-1}$ living branches, $200000 \mathrm{~kg} \mathrm{ha}^{-1}$ stem dry weight, half of which was living biomass, and $20000 \mathrm{~kg} \mathrm{ha}^{-1}$ roots. A typical value for foliage dry weight for Douglas fir in combination with these biomass amounts would be $10000 \mathrm{~kg} \mathrm{ha}^{-1}$. This corresponds to a value for LAI of around 6-7 $\mathrm{m}^{2} \mathrm{~m}^{-2}$. Turnover rates for the biomass components were derived from Goudriaan (1986a) and Mohren (1987).

Soil properties were considered optimal in the model, and a situation of potential production was assumed; in this case, potential growth is entirely determined by radiation and temperature, in combination with physiological properties of the species.

The model was run for several needle mortality rates and needle area distributions. Total annual dry matter production was used as the main trait to evaluate the underlying assumptions. An evaluation of the validity of the calculation of total stand growth was published earlier (Mohren, 1987).

\section{Results}

Figure 3 shows the daily assimilation and dry matter production rate during the year as simulated by the model, with long-term monthly average weather data as input. Low light intensities and low temperatures result in low photosynthesis rates during

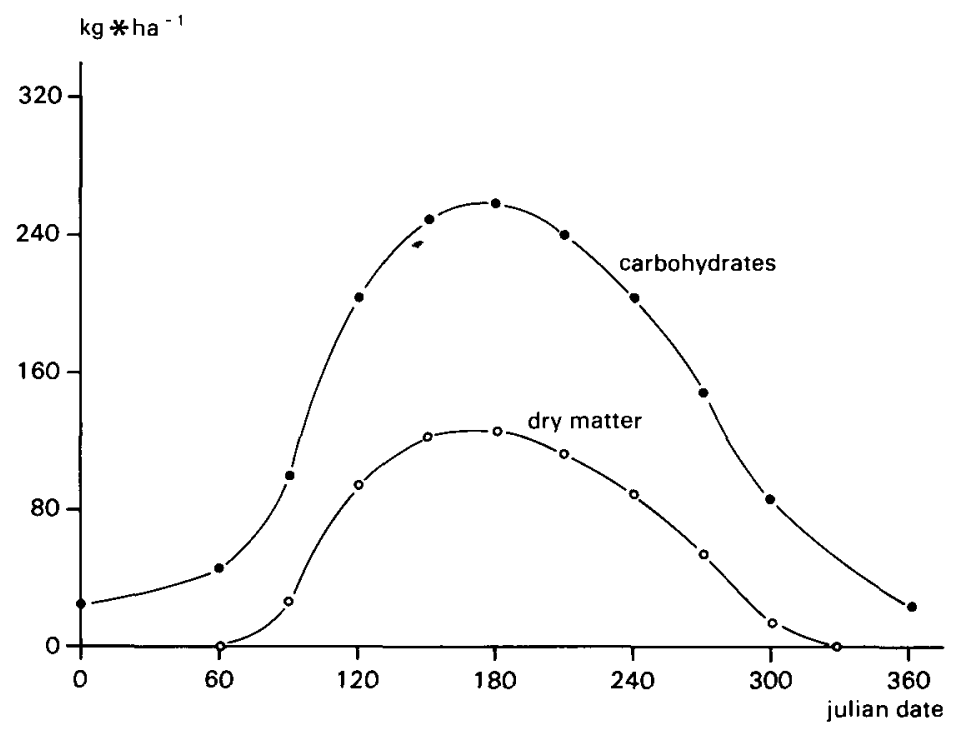

Fig. 3. Daily assimilation $\left(\mathrm{CH}_{2} \mathrm{O}\right)$ and dry matter production rate during the year. Mean values for daily temperature and radiation were used. Time of the year in Julian date. 


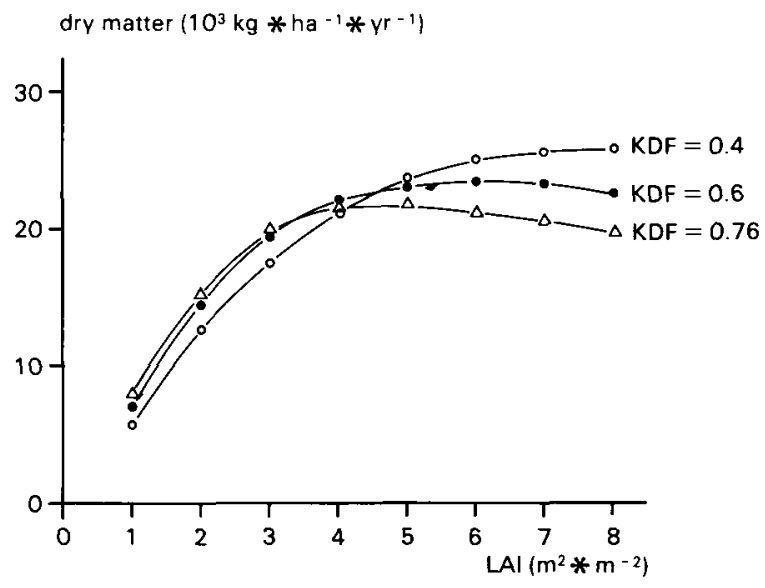

Fig. 4. Annual total dry matter production for different fixed values of the LAI, assuming different extinction coefficients for diffuse light $\left(k_{\mathrm{df}}\right)$. Annual production given here is calculated as the average over a five-year period, with LAI held constant during the simulation. Long-term monthly means for temperature and radiation were used in the simulations; the weather data were taken from the Wageningen meteorological station.

the winter period; the main growing season runs from the end of April (budflush) until the beginning of October. The costs of maintenance respiration match canopy assimilation during the winter period, and net growth is zero.

As total annual dry matter production correlates strongly with the total amount of intercepted radiation, LAI will largely determine the production level of the stand, because LAI determines the fraction of radiation absorbed. This is shown in Figure 4, where the results of annual total dry matter production for different fixed values of LAI in combination with different values for the extinction coefficient are given.

In Figure 5, the effects of increased needle mortality were simulated for two different initial values of LAI. Needle mortality rate was varied by choosing different values for the loss coefficient $L_{\mathrm{c}}$. Initial values for leaf area index were 2.0 and $7.0 \mathrm{~m}^{2} \mathrm{~m}^{-2}$, respectively. As the composition of the living biomass was kept the same for all simulation runs, in most simulations these initial values of LAI were not balanced with the rest of the living biomass. Under the conditions defined here, the model would simulate a leaf area index of about 7 in combination with an $L_{\mathrm{c}}$ value of $3 \times 10^{-6 \mathrm{~d}^{-2}}$ at age 40 . An increase in $L_{\mathrm{c}}$ leads to higher needle loss, hence to a decrease in LAI, when the simulation is started with a high initial leaf area index. This is shown in Figure 5 where LAI at the end of the year is given as well. With a loss coefficient of $2.5 \times 10^{-6} \mathrm{~d}^{-2}$, LAI increases somewhat from 7.0, becoming $7.3 \mathrm{~m}^{2} \mathrm{~m}^{-2}$ at the end of the year. At values for $L_{\mathrm{c}}$ of $5.0,7.5$, and 10.0 $\times 10^{-6} \mathrm{~d}^{-2}$, LAI decreases from 7.0 to $6.4,5.8$, and $5.4 \mathrm{~m}^{2} \mathrm{~m}^{-2}$, respectively.

When the simulation is started with a value of less than 7.0 for LAI, LAI will generally increase, also with values for $L_{c}$ that are higher than $3.0 \times 10^{-6} \mathrm{~d}^{-2}$. 


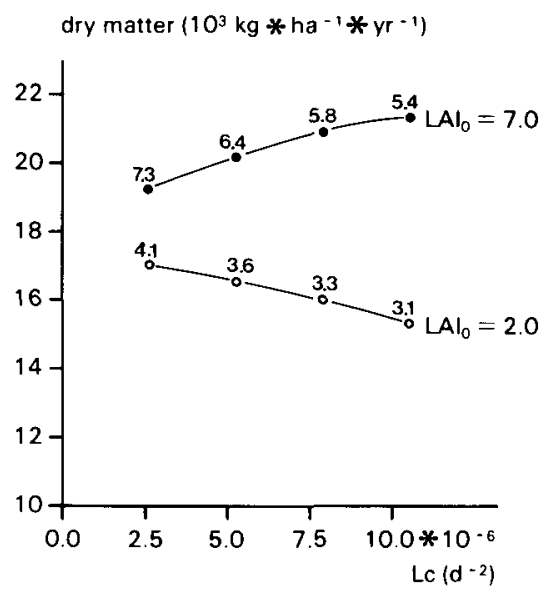

Fig. 5. The influence of initial LAI ( $\mathrm{LAI}_{0}$ on the effects of increased needle mortality rates of annual total dry matter production. $L_{\mathrm{c}}$ is the loss coefficient (see Equation 2). All points on the lines represent model results for one-year calculations only, all starting with $\mathrm{LAI}_{0}$ equal to either 2.0 or $7.0 \mathrm{~m}^{2} \mathrm{~m}^{-2}$. Values of LAI at the end of the year for initial values of 2.0 and 7.0 and for different combinations with $L_{\mathrm{c}}$ are indicated in the graph. Because of increased needle loss, LAI decreased somewhat during the year in all simulations that were started with a LAI of 7.0, except for the case with $L_{\mathrm{c}}=2.5 \times 10^{-6 \mathrm{~d}-2}$. In all simulations, a homogeneous needle area distribution was used, with an extinction coefficient of 0.76 for diffuse light.

With the parameter values and the initial conditions used here, LAI increases from 2.0 to $4.1,3.6,3.3$, and $3.1 \mathrm{~m}^{2} \mathrm{~m}^{-2}$ for values of $L_{\mathrm{c}}$ of $2.5,5.0,7.5$, and $10.0 \times$ $10^{-6} \mathrm{~d}^{-2}$, respectively. If LAI $=2.0$ would have been balanced with the initial conditions for the simulation run, then an increase in $L_{c}$ would have led to an even larger decrease in total dry matter production than that given in Figure 5, because in that case LAI would have decreased with increased $L_{\mathrm{c}}$ at LAI $=2.0$. This implies that in reality the effect on growth of an increase in $L_{\mathrm{c}}$ at low LAI will be even more pronounced than simulated with the model.

Several different needle mass distributions were used to determine the effect of spatial distribution of needle area on dry matter production, see Figure 6. One distribution was based on field data on Douglas fir published by Borghetti et al. (1986), and two hypothetical distributions were used. In the first hypothetical distribution a pronounced difference in distribution between needle age-classes was assumed: young needles were concentrated in the upper part of the canopy, older needles were mostly located in the bottom half of the canopy. Such a distribution may result when the mean life-span of the needles decreases as a result of the top of the canopy being more af fected by exposure to climatic extremes and air pollution (Zajaczkows$\mathrm{ka}$ et al., 1981). These differences between upper and lower parts of the crown have been found in the Netherlands too (Mohren, 1987).

The second hypothetical distribution represents a situation where all age-classes are concentrated in the upper part of the canopy. This situation would appear when 

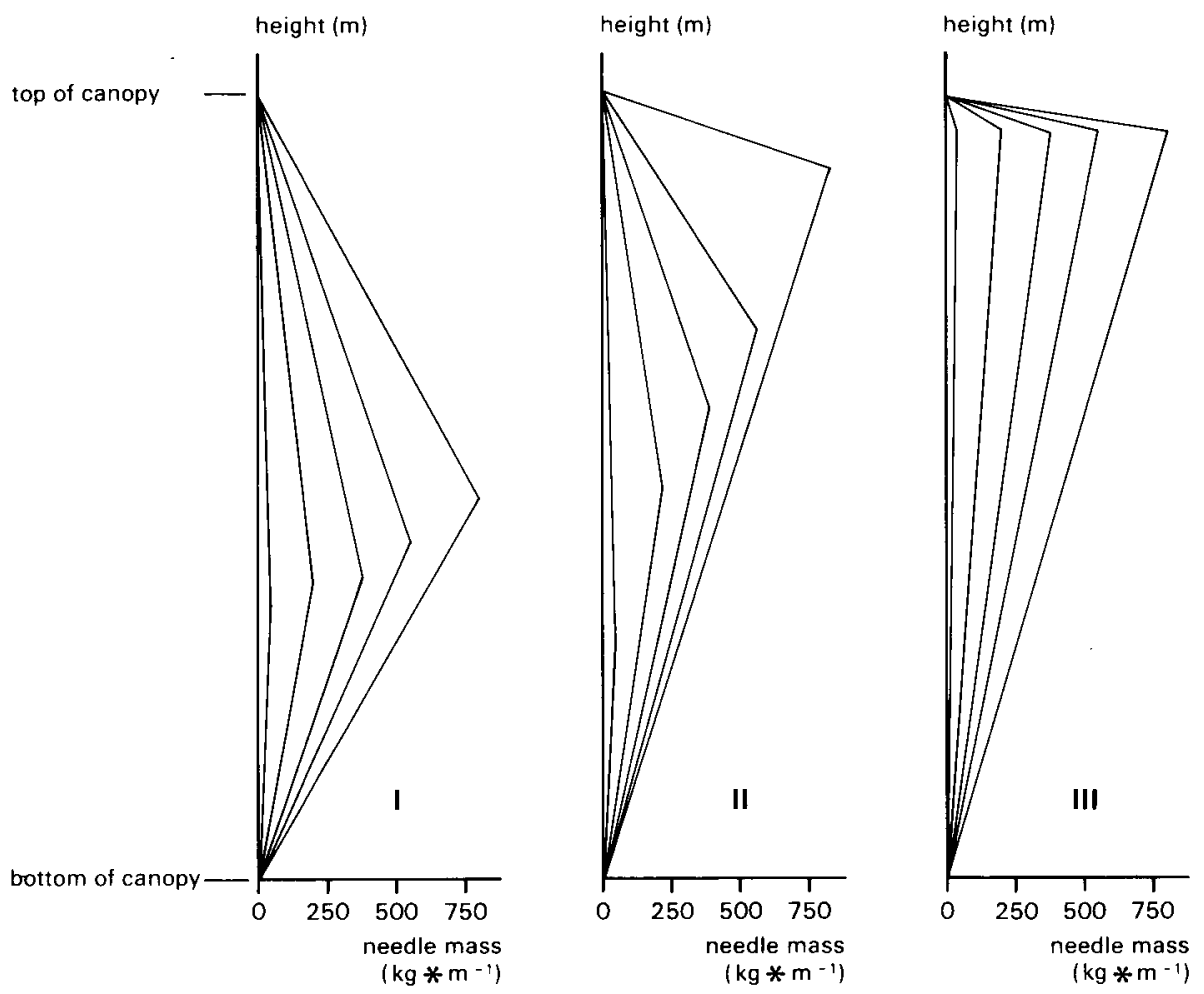

Fig. 6. Needle mass distributions as used in the simulation model. I: based on field data from Borghetti et al. (1986). II and III: Hypothetical distributions; see text for explication.

the main factor determining the life-span of needles is light availability rather than atmospheric conditions such as temperature extremes and low humidity. The results of these simulation runs are given in Table 1. Figure 7 shows the relation between the amount of absorbed light and the resulting annual dry matter production.

Table 1. Simulation results of one-year runs, using different needle age-class distributions. Assimilate and dry matter production are expressed in metric tonnes per hectare per year. For three of the five ageclasses, the fractions of the annual total assimilation were calculated; percentages of the annual totals are given in brackets.

\begin{tabular}{|c|c|c|c|c|c|c|}
\hline \multirow{2}{*}{$\begin{array}{l}\text { Type of } \\
\text { distribution }\end{array}$} & \multirow[t]{2}{*}{ LAl } & \multicolumn{4}{|c|}{ Assimilates per age-class } & \multirow{2}{*}{$\begin{array}{l}\text { Dry } \\
\text { matter }\end{array}$} \\
\hline & & current & 2 year & 4 year & total & \\
\hline I: field data & 6.5 & $13.6(28)$ & $8.4(18)$ & $1.7(3)$ & 48.0 & 19.4 \\
\hline II: 1st hyp. & 6.6 & $16.4(34)$ & $7.4(15)$ & $1.0(2)$ & 48.7 & 19.8 \\
\hline III: 2 nd hyp. & 6.7 & $15.6(29)$ & $9.6(18)$ & $1.9(4)$ & 53.6 & 22.6 \\
\hline
\end{tabular}




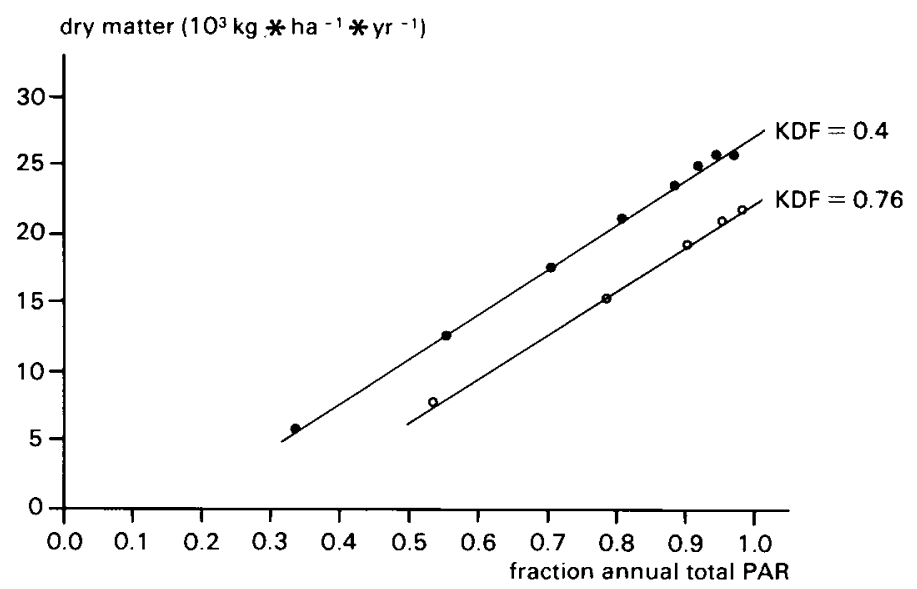

Fig. 7. Relationship between the amount of absorbed photosynthetically active radiation and the annual total dry matter production, calculated for two different extinction coefficients for diffuse light $\left(k_{\mathrm{df}}\right)$. Annual total photosynthetically active radiation is about $1.682 \times 10^{7} \mathrm{MJ} \mathrm{ha}^{-1}$. The intercepts of the lines correspond to the amount of canopy assimilation needed to meet the requirements for maintenance respiration in the stands used here.

Different extinction coefficients were used, representing different degrees of clustering.

Generally, growth rate is proportional to the amount of radiation intercepted by the canopy (Monteith, 1977). Light absorption is mainly determined by the amount of foliage, and thus LAI expresses the growth potential of a forest stand (Jarvis \& Leverenz, 1983; Linder, 1985). The current model simulates that the dry matter production is proportional to the amount of absorbed light. In Figure 7 it was assumed that growth occurs during the growing season (200 days) only. The total amount of light in the Netherlands is $3.363 \times 10^{7} \mathrm{MJ}^{-1}$ annually with about $2.5 \times 10^{7} \mathrm{MJ} \mathrm{ha}^{-1}$ in the growing season. In the model, total photosynthetically active radiation was set to $50 \%$ of the amount of incoming global radiation. The slope of the line in Figure 7 corresponds to the efficiency of dry matter production of the Douglas fir stand. This efficiency was equal to $1.1 \mathrm{~g} \mathrm{MJ}^{-1}$ (dry matter formed per unit of light absorbed) per year or $1.5 \mathrm{~g} \mathrm{MJ}^{-1}$ when only the radiation during the growing season was taken into account. In order to compare this value with results from other studies, the efficiency for the growth of stem dry weight was also calculated, assuming that $45 \%$ of the dry matter increment was converted into stem biomass. Using a specific gravity of $460 \mathrm{~kg} \mathrm{~m}^{-3}$, the efficiency for dry matter production during the growing season was computed to be $14.9 \times 10^{-4} \mathrm{~m}^{3} \mathrm{GJ}^{-1}$. This result is in agreement with results from Linder (1986), who found values of 16.7 $\mathrm{m}^{3} \mathrm{GJ}^{-1}$ for Pinus radiata in Australia and $16.4 \times 10^{-4} \mathrm{~m}^{3} \mathrm{GJ}-1$ for Pinus sylvestris in Sweden. However, the efficiency for dry matter production of Douglas fir is low compared with the values obtained in agricultural crops (up to $3.0 \mathrm{~g} \mathrm{MJ}^{-1}$, Monteith, 1977). 


\section{Discussion and conclusion}

From Figure 5 it appears that the effect of an increased needle mortality rate strongly depends on initial LAI of the stand. This can be explained by the fact that increased needle loss affects canopy assimilation in different ways:

1. A decrease of the total amount of foliage, causing a decrease in light interception.

2. A decrease of the maintenance respiration requirements because of lower foliage biomass.

3. An increase is mean photosynthesis rate per unit foliage area because the amount of less productive foliage decreases.

When initial LAI is low, the effects of the first phenomenon (a decrease in light interception) will dominate, causing the canopy assimilation rate and rate of dry matter production to fall. At high LAI, however, the result may be an increase in dry matter production because of the second and third phenomenon mentioned above: although adsorption of radiation may decrease slightly because of the decrease of LAI, this will have only a minor effect. Average photosynthesis rate will increase and maintenance respiration decreases, and therefore the total amount of assimilates available for dry matter increment will increase.

Spatial distribution of the needle area of the canopy in the model (Table 1) may have a pronounced effect on light interception, canopy assimilation, and total dry matter production. This is because of the effects on light absorption per needle ageclass.

Total intercepted radiation depends on stand LAI. At low LAI, the amount of intercepted radiation increases linearly with increasing LAI. As soon as mutual shading occurs, however, the increase in interception is less than proportional. According to Figure 4, the total amount of light interception attains its maximum at an LAI of 5-6. The saturation level is determined by the rate of light extenction per unit LAI added, which is described by the extinction coefficient. In the case of clustering of needles, which results in a lower extinction coefficient, the optimum occurs at a higher value of LAI. This implies that in coniferous forests where clustering of needles may occur in shoots, around branches, and sometimes within narrow crowns, the optimum value for LAI may be as high as 7 or 8 .

When considering the effect of air pollution on needle longevity and its relevance for total stand growth, the difference in sensitivity between stands with high and low LAI should be taken into account. This is important for example when considering the 'vitality' of trees and stands in relation to growth, because this description of vitality is usually assessed from some indication of changes in total foliage mass. Differences between tree species that have different values of LAI in closed stands must be taken into account. As is shown in this paper, an increased needle mortality rate in stands of species with a high LAI, such as Douglas fir, will have a different effect on growth than in stands of species such as Scots pine that in general have a relatively low LAI. Scots pine stands often have values of $2-4 \mathrm{~m}^{2} \mathrm{~m}^{-2}$ for LAI. To account for these differences, it would be preferable to use more quantitative techniques in inventories of forest decline, such as estimating LAI from measure- 
ments of light interception (e.g. using Lang's method, see Lang \& Xiang, 1986; Lang, 1987).

\section{References}

Beadle, C. L., H. Talbot \& P. G. Jarvis, 1982. Canopy structure and leaf area index in a mature Scots pine forest. Forestry 55: 105-123.

Borghetti, M., G. G. Vendramin \& R. Giannini, 1986. Specific leaf area and leaf area distribution in a young Douglas-fir plantation. Canadian Journal of Forest Research 6: 1283-1288.

Del Rio, E. \& A. Berg, 1979. Specific leaf area of Douglas fir reproduction as affected by light and needle age. Forest Science 25: 183-186.

Evers, P., C. J. M. Konsten \& A. W. M. Vermetten, 1987. Acidification research on Douglas fir forests in the Netherlands (ACIFORN-project). In: P. Mathy (Ed.), Air pollution and ecosystems. Proceedings of an international symposium, Grenoble, 18-22 May 1987, p. 887. D. Reidel Publishing Company, Dordrecht.

Freeland, R. O., 1952. Effect of age of leaves upon the rate of photosynthesis in some conifers. Plant Physiology 27: 685-690.

Goudriaan, J., 1977. Crop micrometeorology: a simulation study. Simulation Monograph. Pudoc, Wageningen, $249 \mathrm{pp}$.

Goudriaan, J., 1986a. Simulation of ecosystem response to rising $\mathrm{CO}_{2}$, with special attention to interfacing with the atmosphere. In: C. Rosenzweig \& R. Dickinson (Eds), Climate-Vegetation Interactions, pp. 68-75. NASA Conference Publication 2240.

Goudriaan, J., 1986b. A simple and fast numerical method for the computation of daily totals of crop photosynthesis. Agricultural and Forest Meteorology 38: 249-254.

Jarvis, P. G., G. B. James \& J. J. Landsberg, 1976. Coniferous forests. In: J. L. Monteith (Ed.), Vegetation and Atmosphere. Vol. 2, Case studies, pp. 171-239, Academic Press, London.

Jarvis, P. G. \& J. W. Leverenz, 1983. Productivity of temperate, deciduous and evergreen forests. In: O. L. Lange, P. S. Nobel, C. B. Osmond \& H. Ziegler (Eds), Encyclopedia of Plant Physiology, New Series, Vol. 12D, Physiological Plant Ecology IV, pp. 233-280. Springer-Verlag, Berlin/Heidelberg.

Kay, M., 1978. Foliage biomass of Douglas fir in a 53-year-old plantation. New Zealand Journal of Forestry Science 8: 315-326.

Kinerson, R. \& L. J. Fritschen, 1971. Modelling a coniferous forest canopy. Agricultural Meteorology 8: $439-445$.

Lang, A. R. G., 1987. Simplified estimates of leaf area index from transmittance of the sun's beam. Agricultural and Forest Meteorology 41 : 179-186.

Lang, A. R. G. \& Y. Xiang, 1986. Estimation of leaf area index from transmission of direct sunlight in discontinuous canopies. Agricultural and Forest Meteorology 37: 229-243.

Linder, S., 1985. Potential and actual production in Australian forest stands. In: J. J. Landsberg \& W. Parson (Eds), Research for forest management, p. 11-51. CSIRO, Melbourne.

Linder, S., 1986. Responses to water and nutrients in coniferous ecosystems. Ecological Studies 61: 180-202.

Mohren, G. M. J., 1987. Simulation of forest growth, applied to Douglas-fir stands in the Netherlands. Doctoral thesis, Wageningen Agricultural University, 184 pp.

Monteith, J. L., 1977. Climate and efficiency of crop production in Britain. Philosophical Transactions of the Royal Society of London, Series B: 277-294.

Silver, G. T., 1962. The distribution of Douglas-fir foliage by age. Forest Chronicle 38: 433-438.

Smith, J. H. G., 1972. Persistence, size and weight of needles on Douglas-fir and Western Hemlock branches. Canadian Journal of Forest Research 2: 173-178.

Spitters, C. J. T., 1989. Weeds: population dynamics, germination and competition. In: R. Rabbinge, S. A. Ward \& H. H. van Laar (Eds), Simulation and systems management in crop protection, pp. 182-216, Pudoc, Wageningen.

Spitters, C. J. T., E. Toussaint \& J. Goudriaan, 1986. Separating diffuse and direct components of global radiation and its implications for modelling canopy photosynthesis. I. Components of incom- 
ing radiation. Agricultural and Forest Meteorology 38: 225-237.

Spitters, C. J. T., H. van Keulen \& D. W. G. van Kraalingen, 1989. A simple and universal crop growth simulator: SUCROS87. In: R. Rabbinge, S. A. Ward \& H. H. van Laar (Eds), Simulation and systems management in crop protection, pp. 147-181, Pudoc, Wageningen.

Zajaczkowska, J., A. Lotocki, H. Morteczka \& D. Witkowska, 1981. Ageing of assimilatory organs of conifers under natural and polluted environmental conditions. Polish Ecological Studies 7: 401-413. 